\title{
Coxsackie B Virus
}

National Cancer Institute

\section{Source}

National Cancer Institute. Coxsackie B Virus. NCI Thesaurus. Code C112243.

A species of non-enveloped, spherical viruses with a capsid with $\mathrm{T}=3$ icosahedral symmetry in the Picornaviridae family and Enterovirus genus. The genome is composed of single-stranded, positive-sense RNA. Coxsackie B viruses are found in humans and cause aseptic mening itis, Bornholm disease, arrhythmias and heart failure via fecal-oral contamination. 